\title{
REDUÇÃO DE CONSUMO DE ENERGIA ELÉTRICA E ADEQUAÇÃO DA ILUMINAÇÃO DAS PLANTAS DE PELOTIZAÇÃO UTILIZANDO TECNOLOGIA LED*
}

Paulo Paranhos Gonçalves Filho' Éric Marçal Moreira²

\section{Resumo}

O trabalho apresenta as etapas e resultados obtidos através do projeto de adequação da iluminação de Usinas de Pelotização da VALE no Complexo de Tubarão em Vitória - Brasil utilizando tecnologia LED (Light Emitting Diode). Foi elaborado um estudo luminotécnico das usinas, assim como levantamento in loco para elaboração do projeto de adequação e substituição das luminárias LED. Houve também um estudo da tecnologia e busca por tipos de luminárias que melhor atenderiam cada área especificamente. Foram feitas medições de potência instalada e iluminância das principais áreas das usinas para posterior comparação com os resultados alcançados. Nas áreas onde a tecnologia LED já foi implantada foi obtida uma redução de $45 \%$ em média no consumo de energia elétrica do sistema de iluminação. Verificou-se também um incremento de até 11 vezes no nível de iluminância além da redução das intervenções por parte da manutenção para substituição e/ou melhora da iluminação. A viabilidade da utilização da tecnologia LED foi confirmada pela redução de custo com energia elétrica, redução de manutenção do sistema de iluminação e aumento da iluminância na área com o consequente aumento de segurança no trânsito de pessoas e execução de atividades.

Palavras-chave: Redução; Energia; lluminação; LED.

\section{REDUCTION OF ELETRIC POWER CONSUMPTION AND ADEQUACY OF LIGHTING OF PELLETIZING PLANTS USING LED TECHNOLOGY}

\section{Abstract}

The paper presents the steps and results obtained through the design adequacy of lighting of VALE's Pelletizing Plants in Tubarão Complex in Victoria - Brazil using LED (Light Emitting Diode) technology. A lighting study of the plants was prepared, as well as on-site survey for preparing the draft suitability and replacement of LED luminaires. There was also a study of technology and search for types of luminaires which better fulfill each area specifically. Measurements of installed electric power and illuminance of the main areas of the plants to be compared with the results achieved were made. In areas where LED technology is already deployed a reduction of $45 \%$ on average in energy consumption of the lighting system was obtained. There was also an increase of up to 11 times the level of illuminance and the reduction in interventions by the replacement maintenance and / or improvement of lighting. The feasibility of the use of LED technology was confirmed by the reduction of cost of electric power, reduced maintenance and increased lighting illuminance in the area with the consequent increased security of traffic of people and the implementation of activities.

Keywords: Reduction; Electric power; Lighting; LED.

Engenheiro Eletricista, pós graduado em Gestão de Projetos, Engenheiro Pleno na Gerência de Unidade Técnica Usinas I à IV, Vale, Vitória, ES, Brasil.

2 Bacharel em Sistema de Informação, Analista Sênior na Gerência de Unidade Técnica Usinas I à IV, Vale, Vitória, ES, Brasil.

* Contribuição técnica ao 44 Seminário de Redução de Minério de Ferro e Matérias-primas, 15ํ Simpósio Brasileiro de Minério de Ferro e $2^{\circ}$ Simpósio Brasileiro de Aglomeração de Minério de Ferro, 15 a 18 de setembro de 2014, Belo Horizonte, MG, Brasil. 


\section{INTRODUÇÃO}

Com o aumento da concorrência no mercado surgiu também à corrida por redução no custo de produção. Um dos custos fixos de uma indústria é o gasto com energia elétrica, incluindo iluminação. Há também o custo com intervenções da manutenção assim como a preocupação com a segurança das pessoas e bem estar em seu ambiente de trabalho.

Com a intenção de reduzir custos com energia elétrica e intervenções de manutenção na parte de iluminação e aumentar a segurança e bem estar das pessoas das plantas, surgiu a necessidade de elaborar um projeto para adequar toda a iluminação das plantas das Usinas de Pelotização de I à IV da VALE, no Complexo de Tubarão em Vitória.

Inicialmente foi definida a premissa para utilização de luminárias com lâmpadas convencionais - fluorescentes, vapor de sódio e vapor de mercúrio, porém, após estudos preliminares, foi constatado que não haveria redução do consumo de energia elétrica ou até mesmo haveria um acréscimo neste. Optou-se então para se fazer um estudo mais aprofundado da tecnologia LED, quando, logo no início, demonstrou ser a melhor opção para atingir os objetivos do projeto.

\section{MATERIAIS E MÉTODOS}

Por ser uma tecnologia ainda pouco usada no Brasil em área industrial, houve a necessidade de procurar fabricantes e fornecedores no mercado nacional para se conseguir todas as informações necessárias para início dos estudos.

Os fabricantes e fornecedores foram chamados para visita das áreas a serem atendidas no projeto, apresentarem as soluções de mercado e também disponibilização dos arquivos técnicos das luminárias existentes para simulações em softwares para este fim.

Após as simulações de algumas áreas, foram adquiridas luminárias e lâmpadas LED para instalação em alguns locais para confirmação, através de medições com a utilização de Luximetro, dos dados apresentados pelos softwares.

Foram feitos cálculos para determinação teórica da redução do consumo de energia elétrica com as luminárias e também medições, após instalação de luminárias em algumas áreas, nos transformadores de iluminação que atendem estas.

\section{RESULTADOS E DISCUSSÃO}

As simulações feitas com os dados passados pelos fabricantes se mostraram, em sua grande maioria, reais após a instalação das luminárias em áreas definidas das plantas. Em alguns pontos foi necessário fazer ajuste da instalação devido interferências físicas na área que não foram possíveis serem incluídos nas simulações.

A redução do consumo de energia elétrica também foi confirmada após as medições, sendo considerados valores iguais aos teóricos calculados anteriormente à instalação.

\subsection{Aumento do Nível de lluminamento}

O aumento do nível de iluminamento das áreas foi na ordem de $230 \%$ (Figura 1), deixando as áreas com iluminação bem adequada, aumentando consideravelmente

* Contribuição técnica ao $44^{\circ}$ Seminário de Redução de Minério de Ferro e Matérias-primas, 15은 Simpósio Brasileiro de Minério de Ferro e $2^{\circ}$ Simpósio Brasileiro de Aglomeração de Minério de Ferro, 15 a 18 de setembro de 2014, Belo Horizonte, MG, Brasil. 
a segurança para o trânsito das pessoas e para a manutenção nos equipamentos, assim como aumento do bem estar das pessoas na área e melhora nas inspeções (Figura 2).

Em muitos pontos das áreas houve a necessidade de aumentar o número de luminárias da instalação para adequar a distribuição do nível de iluminamento e/ou iluminar locais que, originalmente, não possuía pontos de iluminação.

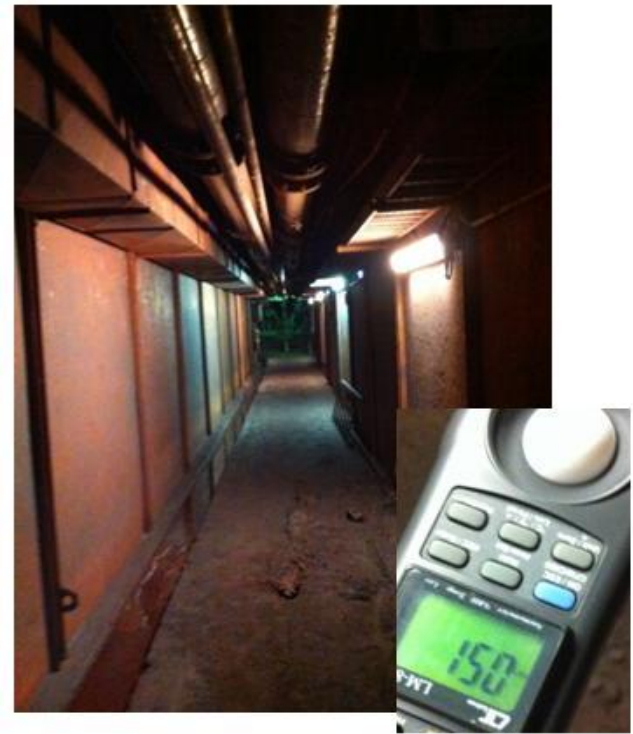

Antes - 150 Lux. Muita área de sombra ao longo da galeria

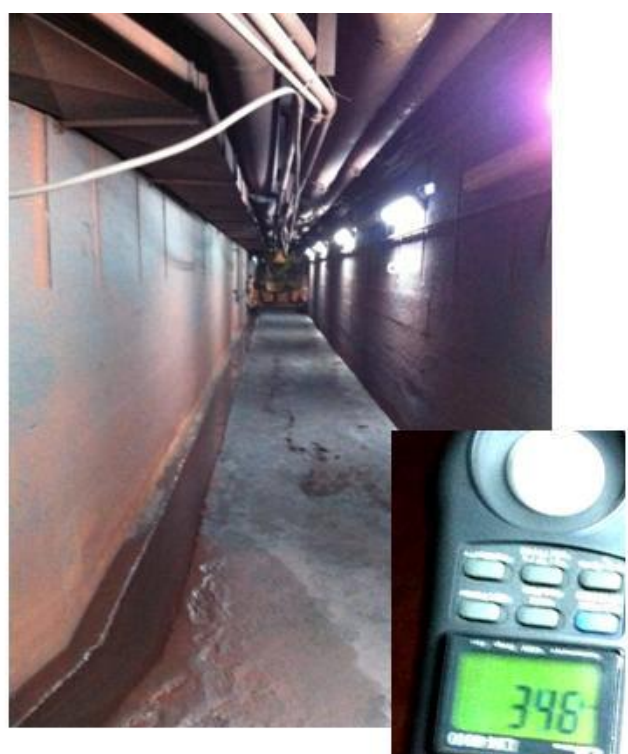

Depois - 346 Lux. Eliminadas áreas de sombra, ficando só penumbras.

Figura 1. Aumento do nível de iluminamento.
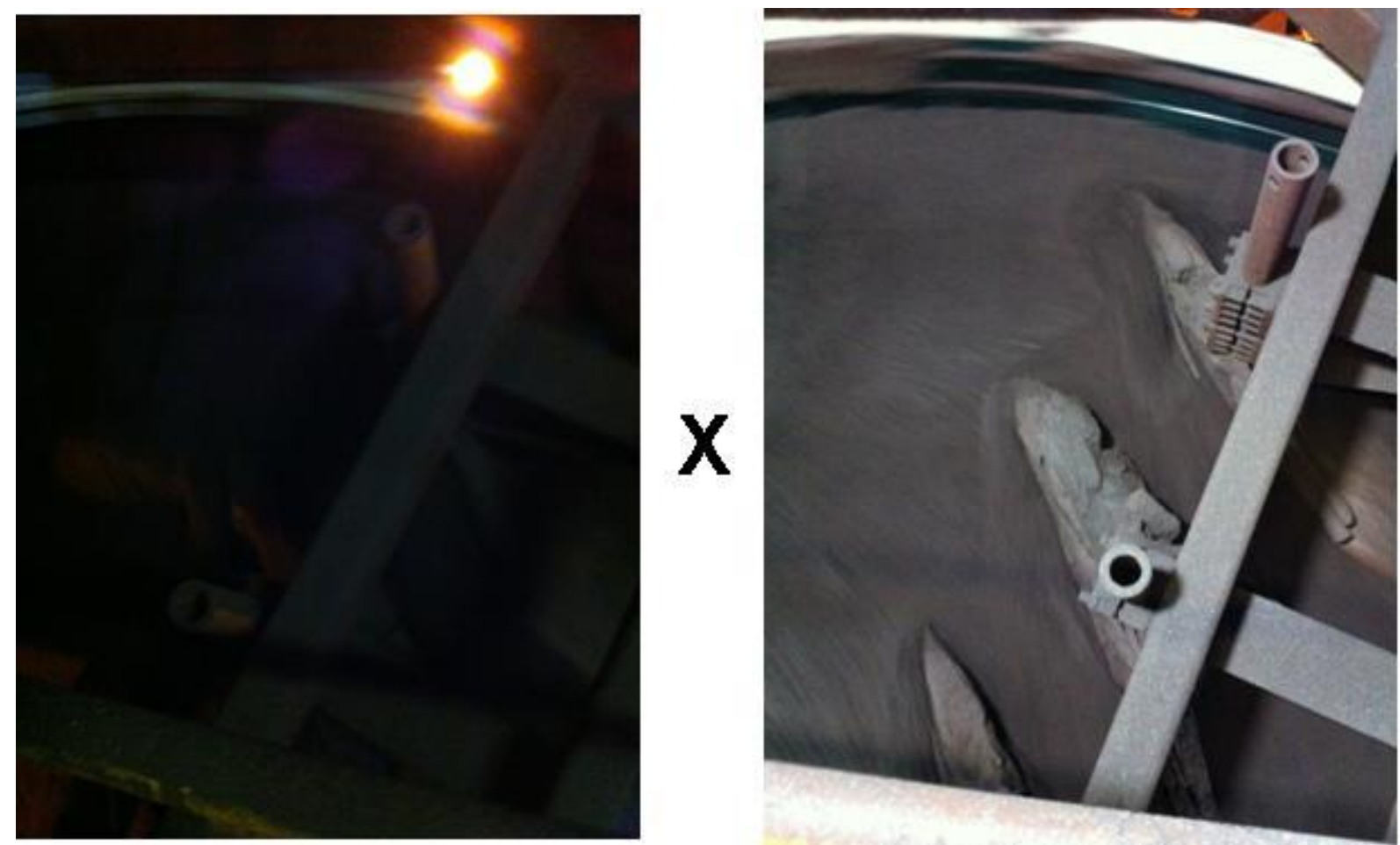

Figura 2. Melhoria para inspeções.

* Contribuição técnica ao 44 Seminário de Redução de Minério de Ferro e Matérias-primas, $15^{\circ}$ Simpósio Brasileiro de Minério de Ferro e $2^{\circ}$ Simpósio Brasileiro de Aglomeração de Minério de Ferro, 15 a 18 de setembro de 2014, Belo Horizonte, MG, Brasil. 


\subsection{Redução do Consumo de Energia Elétrica}

A redução do consumo de energia elétrica pelo sistema de iluminação ficou um pouco abaixo do estabelecido como objetivo no início do projeto, porém houve uma grande queda. Tinha-se como objetivo de redução um valor de $50 \%$ de potência de iluminação instalada, porém, devido a necessidade de instalar novos pontos de iluminação para adequação da iluminação da área, a redução ficou em torno de $41 \%$ nos primeiros locais onde houve a substituição do sistema de iluminação, mas chegou-se ao patamar de 59\% no total já substituído.

Tabela 1. Redução do consumo de energia elétrica nas primeiras áreas

\begin{tabular}{|c|c|c|c|c|c|c|}
\hline & \multicolumn{2}{|c|}{ Espessamento US I e II } & \multicolumn{2}{|c|}{$\begin{array}{c}\text { Discos Pelotamento US } \\
\text { III }\end{array}$} & \multicolumn{2}{|c|}{$\begin{array}{c}\text { Discos Pelotamento US } \\
\text { IV }\end{array}$} \\
\hline & $\begin{array}{c}\text { Sistema } \\
\text { Convencional }\end{array}$ & $\begin{array}{l}\text { Sistema } \\
\text { LED }\end{array}$ & $\begin{array}{c}\text { Sistema } \\
\text { Convencional }\end{array}$ & $\begin{array}{l}\text { Sistema } \\
\text { LED }\end{array}$ & $\begin{array}{c}\text { Sistema } \\
\text { Convencional }\end{array}$ & $\begin{array}{l}\text { Sistema } \\
\text { LED }\end{array}$ \\
\hline Potência (kW) & 2,84 & 1,19 & 4,8 & 1,98 & 4,8 & 1,98 \\
\hline $\begin{array}{l}\text { Vida útil média } \\
\text { (h) }\end{array}$ & 20000 & 50000 & 20000 & 60000 & 20000 & 60000 \\
\hline $\begin{array}{l}\text { Utilização Diária } \\
\text { (h) }\end{array}$ & 24 & 24 & 24 & 24 & 24 & 24 \\
\hline $\begin{array}{l}\text { Utilização Mensal } \\
\text { (dias) }\end{array}$ & 30 & 30 & 30 & 30 & 30 & 30 \\
\hline $\begin{array}{l}\text { Consumo de } \\
\text { Energia Mensal } \\
(\mathrm{kWh})\end{array}$ & 2044,80 & 856,80 & 3456,00 & 1425,60 & 3456,00 & 1425,60 \\
\hline $\begin{array}{lr}\text { Consumo } & \text { de } \\
\text { Energia } & \text { Anual } \\
(\mathrm{kWh}) & \\
\end{array}$ & 24537,60 & 10281,60 & 41472,00 & 17107,20 & 41472,00 & 17107,20 \\
\hline $\begin{array}{l}\text { Redução de } \\
\text { Consumo Mensal } \\
\text { com Iluminação } \\
\text { LED (kWh) }\end{array}$ & \multicolumn{2}{|c|}{$1.188,00$} & \multicolumn{2}{|c|}{$2.030,40$} & \multicolumn{2}{|c|}{$2.030,40$} \\
\hline \multirow{2}{*}{$\begin{array}{l}\text { Residências } \\
\text { Alimentadas } \\
\text { Mensalmente } \\
\text { com } \\
\text { Economizado* }\end{array}$} & \multicolumn{2}{|c|}{7,77} & \multicolumn{2}{|c|}{13,28} & \multicolumn{2}{|c|}{13,28} \\
\hline & \multicolumn{6}{|c|}{34,33} \\
\hline
\end{tabular}

Até o mês de Abril de 2014 já houve, considerando todas as áreas onde houve atuação do projeto, redução total de $46,27 \mathrm{~kW}$ de potência instalada, totalizando uma economia de quase $400 \mathrm{MWh}$ anuais.

\subsection{Redução de Atuação da Manutenção no Sistema de lluminação}

Com a substituição das luminárias convencionais por outras de tecnologia LED, a atuação da manutenção no sistema de iluminação foi nula. Anteriormente a substituição das luminárias, a manutenção era praticamente diária devido a desarmes constantes por conseqüência de problemas nos reatores utilizados assim como para substituição das luminárias e/ou lâmpadas queimadas e/ou em fim de vida útil.

\footnotetext{
* Contribuição técnica ao 44ํ Seminário de Redução de Minério de Ferro e Matérias-primas, 15ํ Simpósio Brasileiro de Minério de Ferro e $2^{\circ}$ Simpósio Brasileiro de Aglomeração de Minério de Ferro, 15 a 18 de setembro de 2014, Belo Horizonte, MG, Brasil.
} 
Devido à agressividade da área (particulados, umidade, temperatura elevada e vibração) havia, com frequência, queima de reatores e lâmpadas e até mesmo folga das lâmpadas nos soquetes das luminárias. Com a utilização das luminárias e lâmpadas LED, estes problemas foram eliminados, gerando maior confiabilidade e disponibilidade do sistema de iluminação.

Por não ter muita atuação da manutenção para correção de problemas do sistema de iluminação, houve também economia com mão-de-obra.

\section{CONCLUSÃO}

Durante a implantação do projeto foi constatado a redução do consumo de energia elétrica com a substituição das luminárias convencionais pelas de tecnologia LED. Estas luminárias, apesar de serem de uma tecnologia pouco difundida em áreas industriais no Brasil, demonstraram ser de boa qualidade, atendendo plenamente a necessidade com ótimo rendimento, robustez e grande vida útil.

\section{BIBLIOGRAFIA}

1 Empresa de Pesquisa Energética - Ministério de Minas e Energia. Anuário estatístico de energia elétrica 2013. 2013 [acessado em 08 abril 2014]. Disponível em: http://www.epe.gov.br/AnuarioEstatisticodeEnergiaEletrica/20130909_1.pdf

* Contribuição técnica ao $44^{\circ}$ Seminário de Redução de Minério de Ferro e Matérias-primas, 15ํ Simpósio Brasileiro de Minério de Ferro e $2^{\circ}$ Simpósio Brasileiro de Aglomeração de Minério de Ferro, 15 a 18 de setembro de 2014, Belo Horizonte, MG, Brasil. 